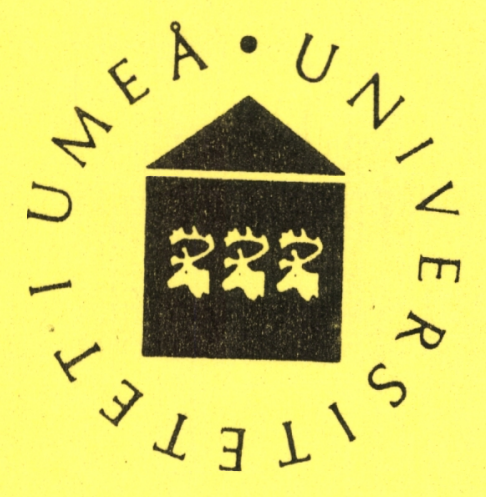

\title{
FIRM AND INDUSTRY COST FUNCTIONS FOR THE CONTROL OF EMISSIONS
} by

Sören Wibe

Umeå Economic Studies No. 155

UNIVERSITY OF UMEA 1985

ISSN 0348-1018 


\section{FIRM AND INDUSTRY COST FUNCIIONS FOR THE CONTROL OF EMISSIONS*}

by

Sören Wibe, University of Umeả

Economic theory, including the economic theory of environmental protection, concentrates on the micro level of the economy. Planners and policy-makers are, on the other hand, more interested in the macro level. The aggregation of micro information to macro relations is, therefore, an important topic for economic research. However, aggregation studies of this kind are rare and usually only micro or macro relations are considered. This applies to both empirical and theoretical studies.

The purpose of this paper is to demonstrate, both theoretically and empirically, the aggregation from micro to macro. Our study object is firm and industry cost functions for emission control in two industries with high pollution levels - Iron \& Steel and Pulp \& Paper. Firm cost functions are estimated using plant data for the period 19691975. These functions are used to construct empirical macro cost functions.

* Financial support from Jacob Wallenberq Research Foundation is gratefully acknowledged. 
The model is built on the assumption of a putty-clay production technology. This seems to be an empirically relevant description of the production structure in most industries. (See 4,6 ). In our case, this means that in each plant the emission control technology is determined by the overall capital structure. The construction of a macro cost function is then essentially a question of ordering firms according to their cost efficiency. This method of ranking firms is used by Sato (7) and by Johansen (4) for the construction of macro production functions. Since we work with only one input ("cost") this ordering becomes very simple.

In section II we set out the main features of the model. The data base is described in section III and micro cost functions are estimated in section IV. Macro cost functions are constructed in section $V$ and some concluding remarks are presented in section VI.

The following symbols are used:

$x^{1}=$ amount of reduced emission at firm i

$x_{0}^{i}=$ initial amount of emission at firm i

$c^{i}=$ cost of reducing emission at firm $i$

$\bar{q}^{i}=$ capacity of firm $i$

$\xi^{i}=$ amount of reduced emission per unit of output at firm $i\left(\xi^{i}=\right.$ $\left.x^{1} / \bar{q}\right)$

$P_{X}=$ "social price" of emission

$C=$ industry cost of reducing emissions

$x=$ amount of reduced emission in industry

$\mathrm{mc}=$ marginal cost

ac $=$ average cost 
$P E=$ particulate emissions

SS = suspended solids

$\mathrm{BOO}_{7}=$ basic oxygen demand

\section{THE MODEL}

The model assumes an industry with $n$ plants producing one homogeneous good and one kind of emission. The amount of discharge produced in the absence of any control arrangements is $x_{0}^{i}(i=1, \ldots, n)$. It is also presumed that each factory has a (least-) cost function for the reduction of emissions: $c^{i}=f^{i}\left(x^{1}\right) i=1, \ldots, n$, where $x^{i}$ is the amount of emission reduced at plant $i .\left(0<x^{i}<x_{0}^{i}\right)$.

The problem is treated as an ex post problem for the plant as a whole. This means that we presuppose that the factoris are already built, and more specifically that plant capacity, $\bar{q}^{i}$, is given. We also assume that the decision on emission control does not influence decisions on production, which we take to be equal to capacity in each plant. This is clearly a simplification, because legislation or the introduction of a charge on emissions will affect production levels in some factories. However, we regard this as a more long-term effect which may enter the decisions concerning the closure of some marqinal firins or the bulding of new ones. An assumption of unchanged production rates seems reasonable in the case of medium-term analyses.

Suppose that we now want to construct a relationship between the total costs $\left(C=\sum C^{l}\right)$ and the total amount of reduced emissions $\left(X=\Sigma x^{1}\right) ; C=$ $F(X)$. Our problem is to find the proper distribution of reductions to 
the different plants, otherwise each level $X$ can be associated with many different cost levels $c$. In order to do this we adopt the rule that the distribution should maximize net social benefits. If the social valuation of emissions ${ }^{1}$ is $B\left(X_{0}-X\right)$, (where $\left.X_{0}=\Sigma x_{0}^{i}\right)$, then we should try to minimize $B\left(x_{0}-X\right)+C(X)$. If we assume a constant marginal valuation of emissions $=P_{X}$, we can formulate our problem as follows:

Minimize $P_{X}\left(\Sigma x_{0}^{i}-\Sigma x^{i}\right)+\Sigma f^{i}\left(x^{i}\right)$

Subject to:

$0<x^{i}<x_{0}^{i}$ $i=1, \ldots, n$

Since we can not assume $\sum f^{i}\left(x^{i}\right)$ to be linear, we have a non-linear programming problem. The solution does, of course, depend on the form of the micro cost functions $f^{i}(x)$. Here we shall only consider the cases in which all the cost functions are monotone, i.e. when $\partial f^{i} / \partial x^{i}$ $>0($ all $i)$ or when $\partial f^{i} / \partial x^{i}<0(a l 1 i)$.

If $\partial f^{i} / \partial x^{i}>0$, i.e. if all marginal cost curves are increasing, then our objective function is convex and the problem fulfills the ArrowEindhoven sufficiency conditions. (2, p. 730-31). Applying the KuhnTucker conditions to our problem, we can deduce the following wellknown rules:

1 We assume that society has a negative valuation of emissions so that $B\left(X_{0}-X\right)$ is the cost to society of emission level $x_{0}-X$. 
$m c^{i}>P_{x}$ for all $x^{i}>0$

$m c^{i}=P_{x}$ for some $x_{1}^{i}$;

$m c^{i}\left\langle P_{x}\right.$ for all $x^{i}>x_{0}^{i}$
$\Rightarrow \quad x^{i}=0$

$\left(0<x_{1}^{1}<x_{0}^{1}\right) \quad \Rightarrow \quad x^{1}=x_{1}^{1}$

$\Rightarrow \quad x^{1}=x_{0}^{i}$

These rules are sufficient for a complete determination of the macro cost function. Each charge $P_{X}$ determines the exact amount of emission control at each plant and hence, through the micro functions $c^{i}=f^{1}\left(x^{1}\right)$, the total costs and the total amount of emission reductions. Increasing the charge succesively from zero, we can obtain all points on our macro function $C=F(X)$.

Suppose now that we have increasing returns to scale in the micro functions, i.e. that the marginal cost curves are falling; $\partial f^{i} / \partial x^{i} \leqslant 0$. (Here we also consider the case with constant marainal cost curves). Since the Arrow-Eindhoven conditions are not satisfied, (if $\partial f^{i} / \partial x^{i}<0$ ) we can not apply the Kuhn-Tucker conditions. However, if we take account of the fact that a total social optimum implies that each firm reduces its emissions to the point where further reductions would cost more than the social valuation, we can easily obtain the following rules ${ }^{2}$ (ac ${ }^{i}$ denotes average cost of emission control, $\left.=f^{i}\left(x^{i}\right) / x^{i}\right)$
$\operatorname{ac}^{i}\left(x_{0}^{i}\right)>P_{x}$
$\Rightarrow$
$x^{i}=0$

2 Observe that $a c^{1}\left(x^{1}\right) \bar{\zeta} m c^{1}\left(x^{i}\right)$ if $\partial f^{i} / \partial x^{i} \bar{\gamma} 0\left(\right.$ since $\left.f^{1}(0)=0\right)$. 


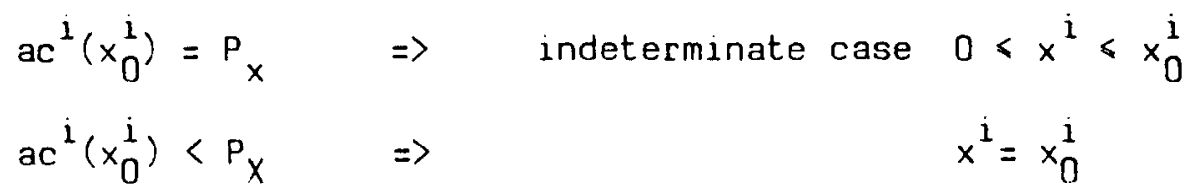

These rules also allow a complete determination of the amount of emission control at each plant. We observe that we have a discrete behaviour in this case; firms switch between zero and complete reduction when the charge passes the critical level. This critical level is determined by the average control cost for complete reduction. The construction of a macro function $C=F(X)$ is simpler in this case than in the former, as we now only have to order the plants according to the average cost of full emission reduction.

III THE DATA BASE

Data for the empirical illustrations were obtained from Facht (3). His data were in turn collected at the Environinental Protection Board in Sweden. Facht's data refers to plant observations in the Pulp \& Paper and the Iron \& Steel industries in Sweden. The data used for this study (see appendix) are:

\section{(1) For the Pulp \& Paper Industry:}

1) Plant capacity in 1975 (1000 tons/year)

2) Amount of suspended solids (SS) in 1969 and 1975 (kg/ton)

3) Amount of Basic Dxygen Demand $\left(\mathrm{BOO}_{7}\right)$ in 1969 and 1975 ( $\mathrm{kg} / \mathrm{ton}$ ) 
4) Annual costs of reducing discharqes (SS+BOD) from 1969 level to 7

1975 level. These costs include variable costs and capital costs. Capital costs were calculated as an annuity of 0.1627 of total capital outlay. (10 years depreciation period and $10 \%$ interest. See Facht, p. 74). All costs are in 1000 SEK 1972 price level.

A total of 40 pulp-producing plants were used for this study.

\section{(ii) For the Iron \& Steel Industry}

1) Capacity, same as for $P \& P$.

2) Amount of particulate emissions (PE) in 1969 and 1975 ( $\mathrm{kg} /$ ton)

3) Amount of suspended solids (SS) in 1969 and 1975 ( kg/ton)

4) Annual costs of reducing discharges from 1969 to 1975 level. Methods of measurement and units are the same as for the $P$ \& $P$. The cost is divided into the reduction of PE or SS.

A total of 20 plants were used for this study.

IV FIRM COST FUNCIIONS

IV:1 General considerations

First, an investigation of the general shape of the cost-curves was carried out. 3 Special attention was paid to the nature of the marginal cost-curves. A priori we assumed that the mc-curves would increase 
(with reduced amount of emissions) and specifically that marqinal cost would increase when purifying approached $100 \%\left(x^{i}+x_{0}^{i}\right)$. However, we were not able to find any such tendencies. For Iron \& Steel, the slope of the mc-curves were significantly negative for both kinds of emissions. The result was the same for $\mathrm{BOO}_{7}$ in the Pulp \& Paper industry. Only for SS in the Pulp \& Paper industry could a weak tendency be detected for the mc-curve to increase in some models. However, the tendency was statistically insignificant, and should be compared with the significantly negatively sloped mc-curves found in other models. ${ }^{4}$

The general form finally choosen for the micro cost functions (see appendix) was:

$c=f\left(\bar{q}, \xi_{1}, \xi_{2}\right)$

where $\bar{q}=$ plant capacity 1975 and $\xi_{j}=$ reduction 1969-1975, of emission $j$ measured as the difference between 1969 emission value (kg/ton) and 1975 emission value (kg/ton). The cost figure accordingiy refers to the total reduction of $\bar{q} \cdot \xi_{j}$ emission units.

4 Our result contradict conventional wisdom and might be due to an insufficient data base. It is for instance possible that the mccurves really fall until purifying is close to limit $\left(x^{1} / x_{0}^{1}+1\right)$ and that they then rise sharply. Our data are not detailed enough to detect such tendencies and this might explain our results. 
Different specifications of $f()$ were used for the two industries. Since only one cost measure was avallable for the reduction of two kinds of emissions in the Pulp \& Paper industry, it was necessary to choose a non-linear function: 6

$c=(\bar{q})^{a} \cdot\left(a_{2}\left(\xi_{1}\right)^{a_{3}}+a_{4}\left(\xi_{2}\right)^{a_{5}}\right)$

The parameters $a_{1}-a_{5}$ were estimated by non-linear least square regression. The results were:

Table 1 Non-linear estimate of cost function for the Pulp \& Paper

$$
\begin{aligned}
& \text { Industry: } c=(\bar{q})^{a_{1}} \cdot\left(a_{2} \cdot\left(\xi_{1}\right)^{a_{3}}+a_{4}\left(\xi_{2}\right)^{a_{5}}\right) . \\
& \left(\xi_{1}=\text { suspended solids, } \xi_{2}=800_{7}\right) .
\end{aligned}
$$

\begin{tabular}{llllll}
\hline Parameter & $a_{1}$ & $a_{2}$ & $a_{3}$ & $a_{4}$ & $a_{5}$ \\
\hline Estimate & 0.728 & 3.00 & 0.665 & 9.45 & 0.322 \\
$($ t-ratio $)$ & $(5.97)$ & $(1.05)$ & $(2.61)$ & $(1.07)$ & $(1.63)$ \\
\hline
\end{tabular}

The log-likelihood function was -46.74412 and the ML estimate of

5 The micro functions estimated below are, of course, only approximations. For more exact empirical analyses, see $(5,8,9)$ for the Steel industry and ( 3 ) for the Pulp \& Paper industry.

6 It was desirable to choose a function with the followina properties: $f(\bar{q}, 0,0)=0 ; f\left(\bar{q}, \xi_{1}, 0\right) \neq 0$ if $\xi_{1} \neq 0$ (and the same for $\left.\xi_{2}\right)$. 
sigma-square was 0.60612 .7

Ignoring the last fiqure in the parameter estimates, we obtain for the marainal (mc) and average cost (ac) functions:

$$
\begin{aligned}
& m c\left(x_{1}\right)=(\bar{q})^{0.08} \cdot(3.00) \cdot(0.66) \cdot\left(x_{1}\right)^{-0.34} \\
& m c\left(x_{2}\right)=(\bar{q})^{0.40} \cdot(9.45) \cdot(0.32) \cdot\left(x_{2}\right)^{-0.68}
\end{aligned}
$$

$$
\begin{aligned}
& \operatorname{ac}\left(x_{1}\right)=m c\left(x_{1}\right) / 0.66 \quad\left(\text { NOTE: } x_{2}=0\right) \\
& \operatorname{ac}\left(x_{2}\right)=m c\left(x_{2}\right) / 0.32 \quad\left(\text { NOTE: } x_{1}=0\right)
\end{aligned}
$$

Both marginal and average cost curves are falling over the whole area of definition. The micro cost functions accordingly show returns to scale. It should also be observed that marginal and average costs increase with capacity when the amount of reduced emissions are constant but since $x_{j}=\xi_{j} \cdot \bar{q}$, that costs fall with capacity if reductions per unit of output $\left(\xi_{j}\right)$ are held constant.

\section{3 Firm cost functions for Iron \& Steel}

The cost functions for the Iron \& Steel Industry are simpler since each kind of emission ( $P E=1$ and $S S=2$ ) is associated with a specific cost figure. The function choosen was:

7 A plot of observation (c) vs model prediction $(\hat{c})$ is shown in the appendix. The simple correlation between $c$ and $\hat{c}$ was $G .817$. 
and $a_{1}-a_{3}$ could be estimated by ordinary least-square regression when the function was expressed in a linear form. The results of these regressions are shown in table 2 below:

Table 2 Linear regression of cost functions for the Iron \& Steel

$$
\begin{aligned}
& \text { Industry: } c=a_{1} \cdot(\bar{q})^{a_{2}}\left(\xi_{j}\right)^{a_{3}}, j=1,2 \\
& (j=1 \text { particulate emissions, } j=2 \text { suspended solids). }
\end{aligned}
$$

\begin{tabular}{|c|c|c|c|c|c|}
\hline & & $\ln a_{1}$ & $a_{2}$ & $a_{3}$ & $\operatorname{Adj} R^{2}$ \\
\hline $\begin{array}{l}\text { Particulate } \\
\text { emissions }\end{array}$ & $\begin{array}{l}\text { Estimate } \\
\text { (t-ratio) }\end{array}$ & $\begin{array}{l}0.998 \\
(0.85)\end{array}$ & $\begin{array}{l}0.9026 \\
(4.73)\end{array}$ & $\begin{array}{l}0.5732 \\
(2.18)\end{array}$ & 0.583 \\
\hline $\begin{array}{l}\text { Suspended } \\
\text { solids }\end{array}$ & $\begin{array}{l}\text { Estimate } \\
(t-\text { ratio })\end{array}$ & $\begin{array}{l}2.948 \\
(2.87)\end{array}$ & $\begin{array}{l}0.6143 \\
(3.20)\end{array}$ & $\begin{array}{l}0.3622 \\
(1.14)\end{array}$ & 0.485 \\
\hline
\end{tabular}

Ignoring all but two figures in the parameter estimates, we obtain for $\mathrm{mc}$ and ac:

$$
\begin{array}{ll}
\mathrm{mc}\left(x_{1}\right)=2.71 \cdot(\bar{q})^{0.33} \cdot(0.57) \cdot\left(x_{2}\right)^{-0.43} \\
m c\left(x_{2}\right)=19.06 \cdot(\bar{q})^{0.25} \cdot(0.36) \cdot\left(x_{1}\right)^{-0.64} \\
\operatorname{ac}\left(x_{1}\right)=m c\left(x_{2}\right) / 0.57 & \left(\text { NOTE: } x_{1}=0\right) \\
a c\left(x_{2}\right)=m c\left(x_{1}\right) / 0.36 & \left(\text { NDTE: } x_{2}=0\right)
\end{array}
$$

(The shape of these cost-curves are the same as for the $P$ \& $P$ curves, and the reader is referred to the comments qiven in the earlier section). 


\section{V:1 General considerations}

It was shown in section IV that all $\mathrm{mc}$ - and ac-curves were falling. According to the rules established in section II, this means that elther zero emissions or complete cleaning (at the firm level) is in accordance with our optimality conditions. An ordering of firms according to average (firm) cost for complete reduction allows a de.. termination of the relation between the total amount of emission reduction and the implicit "social price". This is illustrated in tables 3 and 4 using the 1969 figures of total amount of emissions and 1975 capacity figures (see appendix). Table 3 for example, shows that $181000 \mathrm{~kg} S S$ would be reduced in the $P$ \& $P$ industry if a charge of 0.25314 (SEK $/ \mathrm{kg}$ ) was imposed on the industry. (Provided of course that the economy behaved in accordance with the rules of a competitive economy). This charge would make $100 \%$ cleaning profitable in 9 plants whereas the remaining 31 would consider any cleaning unprofitable. A charge of $1.45 \mathrm{SEK} / \mathrm{kg}$ is necessary in order to remove all emissions. However $90 \%$ (210 000 ton) can be removed with a charqe $\approx 0.3 \mathrm{SEK} / \mathrm{kg}$. 
Table 3 Estimated macro cost relations for the reduction of emissions from the Paper \& Pulp Industry.

$\mathrm{Cl}=$ Marginal macro cost SEK $/ \mathrm{kg}$ emission (= Average plant cost for SS)

$C 2=$ Total amount of reduced emission (tons of SS)

C3 = Marginal macro cost (SEK/kq) (BOn)

$\mathrm{C} 4=$ Total amount of reduced $\mathrm{BOO}_{7}$ (tons)

C1

$\mathrm{C} 2$

C3

C4

\begin{tabular}{|c|c|c|c|}
\hline .19126 & 175323. & .056519 & 49353. \\
\hline . 13486 & 138490. & 660817 & 111523. \\
\hline 20798 & 147479. & .088681 & 126007. \\
\hline .21678 & 154999. & .090976 & 152017 \\
\hline S1755. & $16087 \mathrm{~b}$. & .095558 & 164788. \\
\hline .21757 & 167126. & .097438 & 176524. \\
\hline .23944 & 172476. & .104996 & 200652 . \\
\hline .25143 & 177117. & .106117 & 203451. \\
\hline $.253: 4$ & 181000. & .112058 & 239913. \\
\hline .23204 & 185055. & .128425 & 235257. \\
\hline .26227 & 189550. & .132397 & 250032. \\
\hline .25528 & 192651. & .152434 & 254040. \\
\hline .26384 & 195707. & .155709 & 263737. \\
\hline .27227 & 198831. & .155407 & $2766 ! 5$. \\
\hline .28244 & 201024. & .164300 & 204372. \\
\hline $.2936 ?$ & 204567. & .166741 & 290807 \\
\hline 28796 & 206637. & .171710 & 302497. \\
\hline .28761 & 203785. & $.17331 !$ & 309359. \\
\hline .29898 & 211377 & .173630 & 312029. \\
\hline .30082 & 213676. & .192998 & 326065 \\
\hline$\therefore 9983$ & 216526. & .193071 & 334540. \\
\hline .31447 & 218206. & .998060 & 337264. \\
\hline . 32192 & 220177. & .200969 & 348193. \\
\hline .326033 & 222571. & .202290 & 358987 . \\
\hline .33201 & 223359. & .206993 & 364037. \\
\hline .30520 & 225622. & .21959? & 370877. \\
\hline . & 225939. & .221232 & 381377. \\
\hline $.336 ? 4$ & 220657. & .238731 & 336382. \\
\hline .33716 & 230052. & .2300396 & 38313. \\
\hline .34652 & 231714 & .291570 & 391031. \\
\hline .3143 & 232514 & 300906 & 394649. \\
\hline .29534 & 233444. & .327932 & 395672. \\
\hline .48879 & $23393 ?$. & .35474 & 397142. \\
\hline .50358 & 234300. & .434604 & 398359. \\
\hline 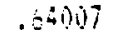 & 234462. & .446145 & 299946. \\
\hline \multirow[t]{5}{*}{6.45243} & $2344 ? 2$. & .250855 & $4(\ln 296$. \\
\hline & & 924205 & inote. \\
\hline & & .5216 & 401685. \\
\hline & & .292279 & $40198 ?$ \\
\hline & & 24512 & 409007 \\
\hline
\end{tabular}


Table 4 Estimated macro cost relations for the reduction of emissions from the Iron \& Steel Industry.

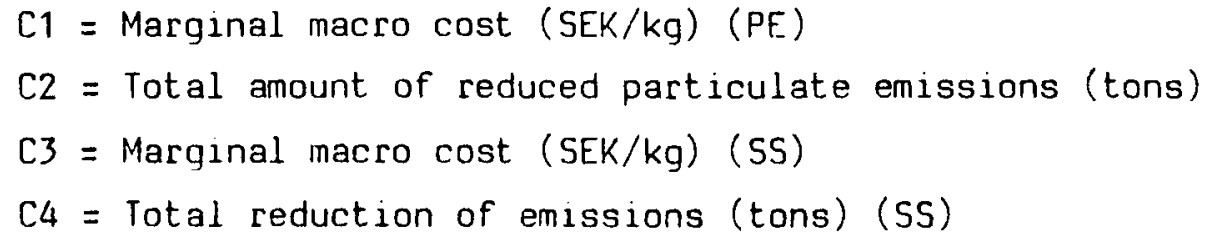

C1

C2

C3

C4

\begin{tabular}{|c|c|c|c|}
\hline .32117 & 10042.0 & . 15747 & 36480.0 \\
\hline . 39193 & 14585.0 & .3376! & $4 E 50.0$ \\
\hline .4289? & !29९3.0 & .53025 & 49284.0 \\
\hline 45542 & 23333.0 & .60155 & 50004.0 \\
\hline .46573 & 23909.0 & .63850 & 55098.5 \\
\hline $\begin{array}{l}.47274 \\
\text { cin7c }\end{array}$ & 45359.0 & .97840 & 56152.5 \\
\hline .51275 & $\begin{array}{l}46374.0 \\
=00939.0\end{array}$ & 1.09278 & $50640 . \hat{v}$ \\
\hline . .52275 & $\begin{array}{l}50938.0 \\
5 ? 579.0\end{array}$ & $1.1322 \mathrm{i}$ & 57394.0 \\
\hline .57281 & 71548.0 & 1.22453 & 57901.0 \\
\hline 60793 & 72755.5 & 1.57188 & $592 ! 3.0$ \\
\hline .64670 & 74764.5 & $1.61 \leq 80$ & 58441.0 \\
\hline .64704 & $773+2.5$ & 2.01362 & 53540.0 \\
\hline .68215 & 79030.1 & 2.10752 & 53710.4 \\
\hline .71272 & 80160.1 & $\therefore 21 / 69$ & $5 a 218.4$ \\
\hline .82455 & 82207.6 & & \\
\hline .87232 & a2618.6 & & \\
\hline .89785 & 82926.6 & & \\
\hline 1.25000 & 33124.6 & & \\
\hline
\end{tabular}


If the actual reductions per unit of production 1969-1975 are kept fixed, we obtain the following emission reductions ${ }^{8}$ together with implicit marginal social valuation.

Table 5 Emission reductions 1969-1975 with implicit marginal social valuation (price)

\begin{tabular}{|c|c|c|c|}
\hline & & $\begin{array}{l}\text { Reductions } \\
\text { (tons) }\end{array}$ & $\begin{array}{l}\text { Social Price } \\
(\text { SEK/kg) }\end{array}$ \\
\hline \multirow{2}{*}{$P \& P$} & SS & 163544 & 0.22 \\
\hline & $\mathrm{BOD}_{7}$ & 203684 & 0.11 \\
\hline \multirow{2}{*}{$I \& S$} & $P E$ & 60866 & 0.59 \\
\hline & SS & 51176 & 0.60 \\
\hline
\end{tabular}

Thus, the I \& $S$ industry reduced emissions as if a charge of 0.60 (SEK/kq) had been imposed.

\section{V:2 Industry cost functions for the Pulp \& Paper industry}

Using the figures in table 3 we can derive a relationohip between industrial (least-) cost and total amount of reduction. Such a relationship is shown in figure 1 for $5 S$. (The figure for $B O D_{7}$ is very similar). The points of figure 1 (and the correspondng for $B O D_{7}$ ) were used to estimate the industrial cost function using the equation:

8 The fiqures are somewhat different from the actual emission reductions during the period since we assume that 1969 capacities equal the 1975 fiqures. 
$c=a_{1} \cdot x^{a_{2}}$

The results (from ordinary least-square regression) are presented in the table below: ${ }^{9}$

Table 6 Estimated macro cost functions for the Pulp \& Paper industry $\ln C=\ln a_{1}+a_{2} \cdot \ln X^{*}$

( $t$-ratio under parameter estimate)

\begin{tabular}{|c|c|c|c|}
\hline Material & $\ln a_{1}$ & $a_{2}$ & $\operatorname{Adj} R^{2}$ \\
\hline Suspended & -7.0981 & 1.438 & 0.995 \\
\hline soluds & $(-36.37)$ & $(89.36)$ & \\
\hline \multirow[t]{2}{*}{$\mathrm{BCD}_{7}$} & -8.8362 & 1.519 & 0.984 \\
\hline & $(-22.59)$ & $(48.80)$ & \\
\hline
\end{tabular}

* C in 1 DoO SEK, $x$ in tons.

Since $a_{2} \approx 1.5$ for both kinds of emissions, we obtain for the elasticity of cost

$(d C / d X) /(C / X) \approx 1.5$

Thus a $1 \%$ increase in emission reductions leads to a $1.5 \%$ increase in $\cos t .10$

9 Observe that the regressions are not made with directly observable data. Data are generated from our micro cost functions and ordered. The regressions are, in these cases, only curve-fitting and the good statistical fit is natural.

in nbserve that the mc-curves for the industry as a whole increase despite the falling mc-curves for each individual firm. 


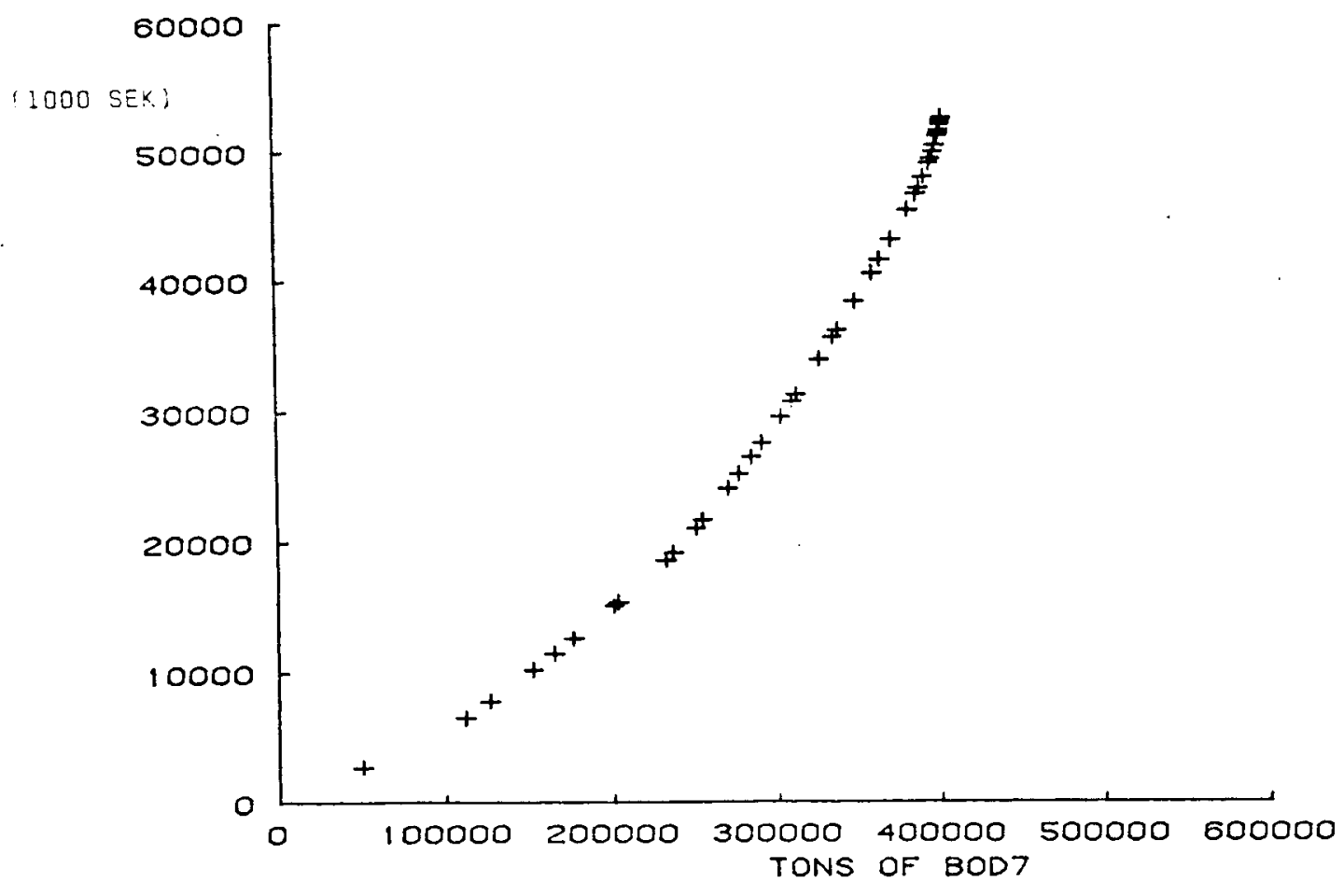

Figure 1 Macro cost function for the reduction of $\mathrm{BOD}_{7}$ in the Pulp \& Paper industry 
$V=3$ Industry cost functions for the Iron \& Steel industry

Industrial cost functions for the Iron \& Steel industry were constructed in the same way as for $P \& P$. In figure 2 , we show the relationship between total costs and reduction of PE. Industry cost functions were estimated using the log-relation. The results are shown in table 7.

Table 7 Estimated industry cost functions for the Iron \& Steel industryll

$\ln c=\ln a_{1}+a_{2} \cdot \ln X^{*}$

\begin{tabular}{llll}
\hline Material & ln $a_{1}$ & $a_{2}$ & Adj $R^{2}$ \\
\hline Particulate & -3.23 & 1.223 & 0.999 \\
emissions & $(-44.71)$ & $(183.14)$ & \\
\hline Suspended & -18.037 & 2.533 & 0.974 \\
solids & $(-14.46)$ & $(22.12)$ & \\
\hline
\end{tabular}

* $C$ in 1000 SEK, $x$ in tons.

Thus the cost-elasticity was around 1.2 for PE, and 2.5 for SS.

11 See footnote 9. 


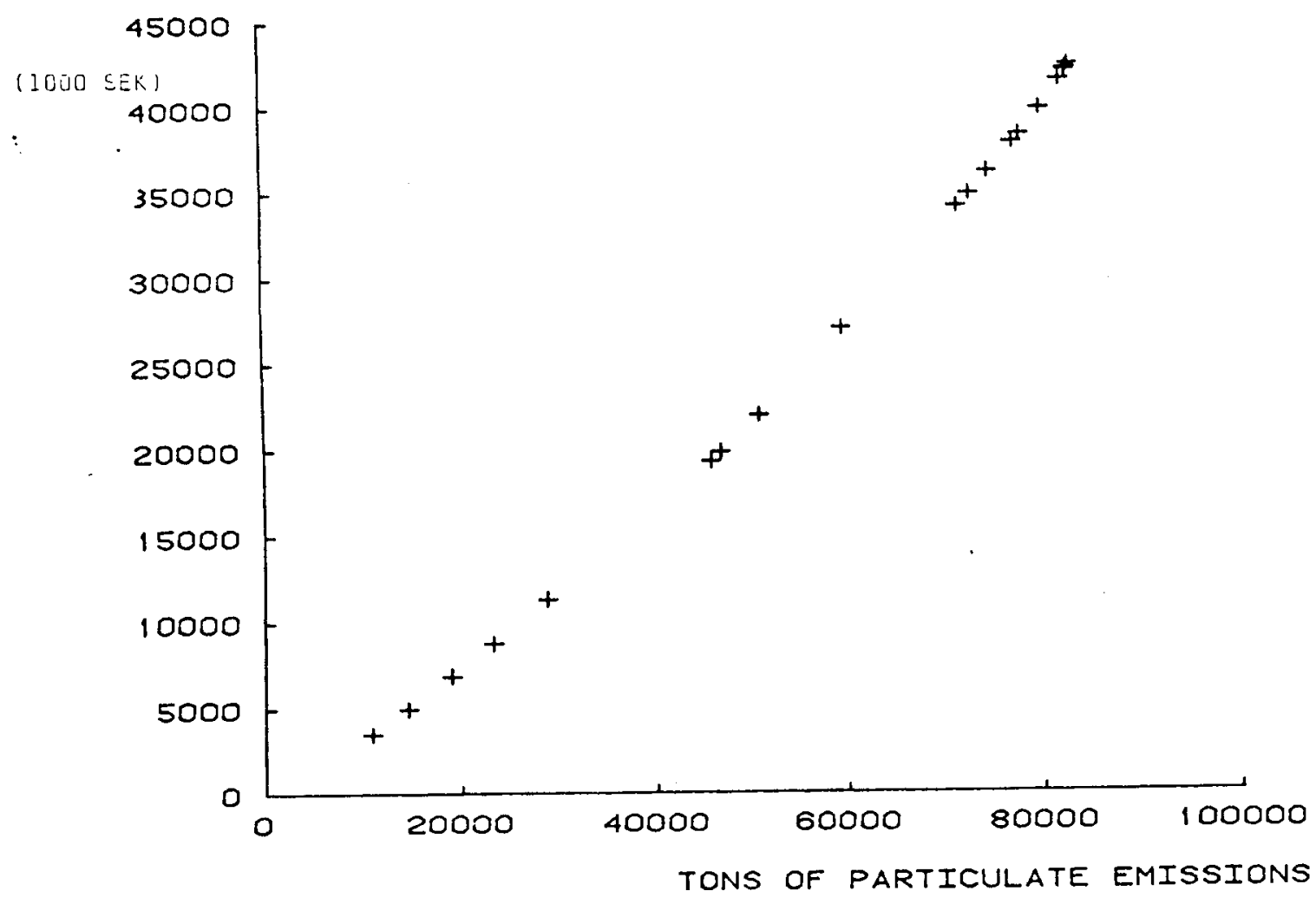

Fiqure 2 Macro cost function for the reduction of particular emissions in the Iron \& Steel industry 
In this paper we have estimated firm cost functions for the control of emissions using plant data from two Swedish industries. These micro cost functions were used to construct macro (or industry) cost functions.

The empirical results show that the average (and marginal) cost-curves at the firm level are falling with the amount of reduction. This result is contrary to engineering evidence and might be due to an insufficient data base. On the industry level, our result shows that the elasticity of cost (with respect to total amount of reduction) is around 1.5 , i.e. that a $1 \%$ increase in reductions means a $1.5 \%$ increase in total costs. 


\section{REFERENCES}

(1) W.J. Baumol and W. E. Dates, The Theory of Environmental Policy. Englewood Cliffs, N.J.: Prentice-Hall, (1975).

(2) A.C. Chiang, Fundamental Methods of Mathematical Economics (2nd ed.). Tokyo: McGraw-Hill, Kogakusha Ltd., (1974).

(3) J. Facht, Emission Control Costs in the Swedish Industry. Stockholm: The Industrial Institute for Economic and social Research, (1975).

(4) L. Johansen, Production Functions. Amsterdam: North-Holland, (1972).

(5) C.S. Russell and W.J. Vaughan, Steel Production: Processes, Products and Residuals. Baltimore: John Hopkin's Press, (1976).

(6) W.E.G. Salter, Productivity and Technical Chanqe. London: Cambridge University Press, (1960).

(7) K. Sato, Production Functions and Aggregation. Amsterdam: North-Holland, (1975).

(8) V.K. Smith and W.J. Vaughan, "The Implications of Model Complexicy for Environmental Mangagement", Journal of Environmental Economics and Management, 7, 184-208, (1980).

(9) V. Thomas, "Welfare Cost of Pollution Control", Journal of Environmental Economics and Manaqement, 7, 90-102, (1980). 


\section{APPENDIX}

\section{$A: 1$}

Data for the Pulp \& Paper Industry

$C 1=$ Plant capacity in 1975 (1000 tons/year)

$C 2=$ Amount of Suspendid Solids 1969 ( $\mathrm{kg} /$ ton pulp)

$\mathrm{C} 3=$ Amount of $\mathrm{BOO}_{7} 1969$ ( $\mathrm{kg} /$ ton pulp)

$C 4=$ Reduction of Suspendid Solids 1969-1975 (ka/ton)

C5 $=$ Reduction of BOD 1969-1975 (kg/ton)

C6 = Annual discharge reduction costs 1969-1975, 1000 SEK 1972 price level

\begin{tabular}{|c|c|c|c|c|c|}
\hline $\mathrm{Cl}$ & $C 2$ & C3 & C4 & C5 & C6 \\
\hline 5.0 & $\because 0 . \vdots$ & 31.0 & $: 2.5$ & 907.0 & 447.0 \\
\hline$\$ 5.0$ & 79.2 & 70.0 & 70.7 & 2.4 & 507.0 \\
\hline 25.0 & 32.0 & 22.0 & 25.3 & 8.0 & 439.6 \\
\hline 30.0 & 67.0 & 87.0 & 84.1 & $29 . \mathrm{i}$ & 2462. \\
\hline 40.0 & 10.0 & 8.0 & 8.7 & 4.4 & 295.0 \\
\hline 300 & 73.1 & 144.8 & jó.t & 109.3 & 167. \\
\hline 3.0 & 37.8 & 8.4 & 36.7 & 5.2 & 85500 \\
\hline 40.0 & 53.7 & SE.1 & 40.5 & 45.1 & 2350 \\
\hline 40.0 & 42.0 & 100.2 & 20.2 & 37.8 & 131.6 \\
\hline$\{5.0$ & $3: 10$ & 38.9 & $7 . !$ & 18.5 & 2077.0 \\
\hline 60.0 & 9.1 & 24.5 & 4.8 & 5.0 & 3210 \\
\hline 70.0 & 44.3 & 17.5 & 23.2 & 2.2 & 540.6 \\
\hline 10.0 & 28.4 & 59.5 & 7.7 & 44.7 & 2447.6 \\
\hline 80.0 & 33.2 & 146.7 & 12.1 & 10.1 & 1961. \\
\hline 105.0 & 21.9 & 65.5 & 17.1 & 26.2 & 2030.0 \\
\hline 90.0 & 65.3 & 160.7 & 54.4 & 52.2 & 5306. \\
\hline 90.0 & 112.6 & 141.9 & 107.1 & 43.2 & 307. \\
\hline $15 E .0$ & 24.6 & 50.7 & 5.0 & 15.3 & 2893. \\
\hline 30.0 & 14.4 & 20.1 & 10.4 & 20.0 & 2528.0 \\
\hline 240.0 & 66.9 & 22.5 & 14.0 & 5.5 & 599 \\
\hline$\$ 45.0$ & 12.2 & 53.5 & 2.3 & b.: & 2486. \\
\hline 590.0 & 5.7 & 21.0 & 1.0 & 2.0 & 8490. \\
\hline 255.6 & 13.2 & 102.0 & 4.7 & 75.7 & 3002 \\
\hline 280.6 & 79.6 & 5.1 & b3.4 & 25.7 & 4194 \\
\hline 230.0 & tul.5 & 214.6 & 93.3 & 207.7 & $20 \%$ \\
\hline 250.0 & 24.4 & $3 . ?$ & 7.8 & 5.6 & 2060 \\
\hline 320.0 & 44.0 & 36.5 & 21.2 & $\div 5$ & 2746 \\
\hline 205.5 & 142.4 & 152.5 & 179.1 & D.3.0 & $011=$ \\
\hline 30.0 & $2 . .5$ & 75.4 & 1.5 & 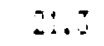 & .755 \\
\hline 430. & $\therefore .7$ & 25.7 &.$\Sigma$ & a..i & $4 E:$ \\
\hline 455.2 & 3.5 & 57.5 & $\therefore$ & $\therefore .9$ & 4233 \\
\hline $27 .:$ & .2 & 3.7 & . & 2E.: & $\because 3$ \\
\hline 125.3 & 5.5 & 42.4 &. & $1 \therefore .2$ & : \\
\hline$E 5$. & 14.2 & $\ldots$ & 4.3 & $\therefore$ & $\cdots$ \\
\hline 175.8 & $\therefore .5$ & :3. & $\begin{array}{l}=7 \\
=5\end{array}$ & . & \\
\hline 110.2 & 5 & :2.7 & $E .5$ & $\therefore 7$ & \\
\hline 19.0 & $\because \div .5$ & $\therefore$. & $\therefore$ & $\therefore$ & \\
\hline 42.3 & $\Xi$ & $\begin{array}{r}Z .1 \\
-5.8\end{array}$ & $\therefore \dot{\xi}$ & ". & \\
\hline $1, \therefore$ & $\begin{array}{r}-1 . \\
\hdashline \therefore .\end{array}$ & $\because 4.2$ & $\therefore$ & $=1$ & \\
\hline
\end{tabular}


Data for the Iron \& Steel Industry

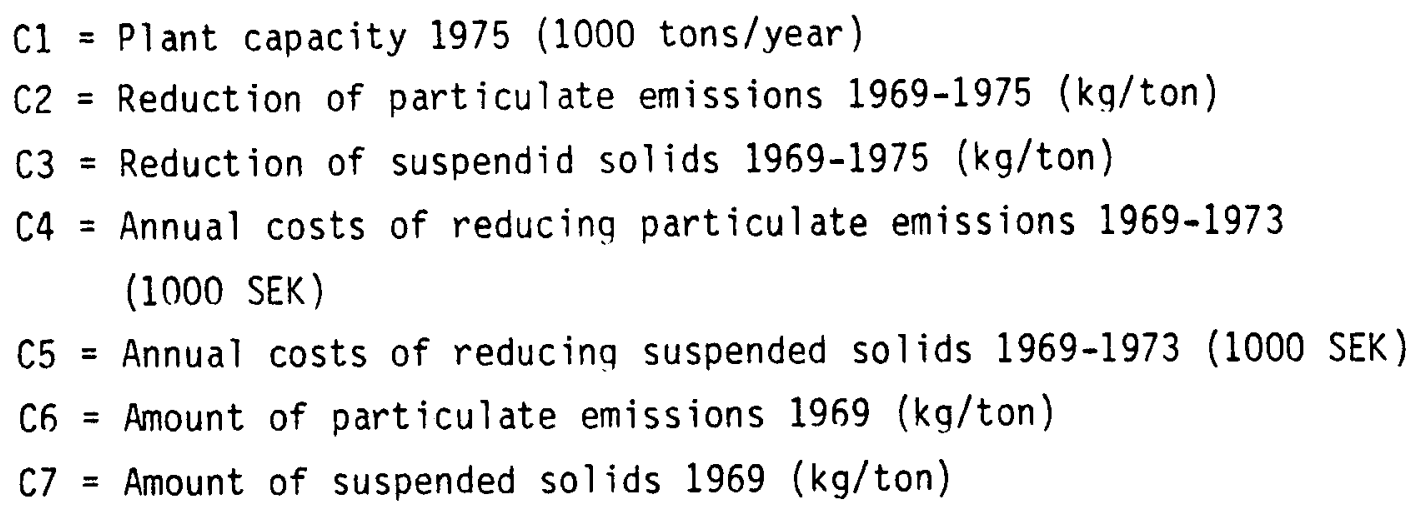


$A: 2$ The shape of the firm cost-curves

In addition to the equations presented on p. $8 \mathrm{ff}$ in the paper, we also tested the following models:

$c^{i}=a_{0}+a_{1} \cdot x^{i}+a_{2} \cdot x^{i} \cdot\left(x^{i} / x_{0}^{i}\right)+a_{3} \cdot a^{-i}$

and

$c^{i}=b_{0}+b_{1} \cdot x^{i}+b_{2} \cdot\left(x^{i}\right)^{2} \cdot\left(x^{i} / x_{0}^{i}\right)+b_{3} \cdot q^{-i}$

For the first function we have

$m c^{i}=a_{1}+a_{2} \cdot x^{i} / x_{0}^{i}$

and for the second

$m c^{i}=b_{1}+b_{2} \cdot x^{i} \cdot\left(x^{i} / x_{0}^{i}\right)$

The variable $x^{i} / x_{0}^{i}$ denotes reduction relative to total possible reduction and was included in order to study the effects on costs when cleaning approached the limit. 
The results for the first equation are shown in the table below:

\begin{tabular}{llllll}
\hline & $a_{0}$ & $a_{1}$ & $a_{2}$ & $a_{3}$ & $R^{2}$ \\
\hline I \& S, PE & 630.6 & 2.43 & -2.41 & -0.308 & 0.706 \\
$(t-v a l u e)$ & $(1.45)$ & $(3.03)$ & $(-2.70)$ & $(-0.25)$ & \\
I \& S, SS & 823 & 2.92 & -2.97 & -0.893 & 0.688 \\
$(t-v a l u e)$ & $(2.27)$ & $(-2.97)$ & $(-2.26)$ & $(-0.60)$ & \\
\hline
\end{tabular}

The results (e.g. falling mc-curves) were roughly the same with the second model.

Since we had only one cost measure and two kinds of emissions, we tested the following model for the $P$ \& $P$ industry: 12

$$
\begin{aligned}
& c^{i}= a_{0}+a_{1} \cdot x_{1}^{i}+a_{2} \cdot\left(x_{2}^{i}\right)^{2} \cdot\left(x_{1}^{i} / x_{10}^{i}\right)+a_{3} \cdot x_{2}^{i}+a_{4} \cdot\left(x_{2}^{i}\right)^{2} \cdot\left(x_{2}^{i} / x_{20}^{i}\right)+ \\
&+a_{5} \cdot \bar{q}^{i} \\
&\left(1=55,2=B 0 D_{7}\right)
\end{aligned}
$$

12 Here we could not work with the variable $x^{1} \cdot\left(x^{1} / x_{0}^{i}\right)$ because of the strona correlation between this variable and $x^{1}$. 
Several modifications of this models were tried. One result (no constant or capacity variable) is shown in the table below: (t-value below estimates)

\begin{tabular}{llllll}
\hline$a_{0}$ & $a_{1}$ & $a_{2}$ & $a_{3}$ & $a_{4}$ & $a_{5}$ \\
\hline & 0.15 & $1.9 \cdot 10^{-6}$ & 0.38 & $-0.9 \cdot 10^{-5}-$ \\
& $(2.2)$ & $(1.52)$ & $(5.64)$ & $(-6.34)$ & \\
\hline
\end{tabular}

Similar results were found in all regressions. The mc-curve was sigrificantly negative for $\mathrm{BOD}_{7}$ and insignificantly positive for SS.13

We finally chose the formulations shown in the paper because of simplicity, goodness of fit and theoretical consistency. These functions have the same general shape as the functions estimated with the linear models presented here. (Except perhaps for SS in $P$ \& $P$ ).

The goodness of fit of the nonlinear model (table 1) are shown in the figure below. The simple correlation between observed value and model prediction was 0.817 .

13 Non-linear models gave a significantly negative mc-curve also for SS. See the estimate in table 1 . 


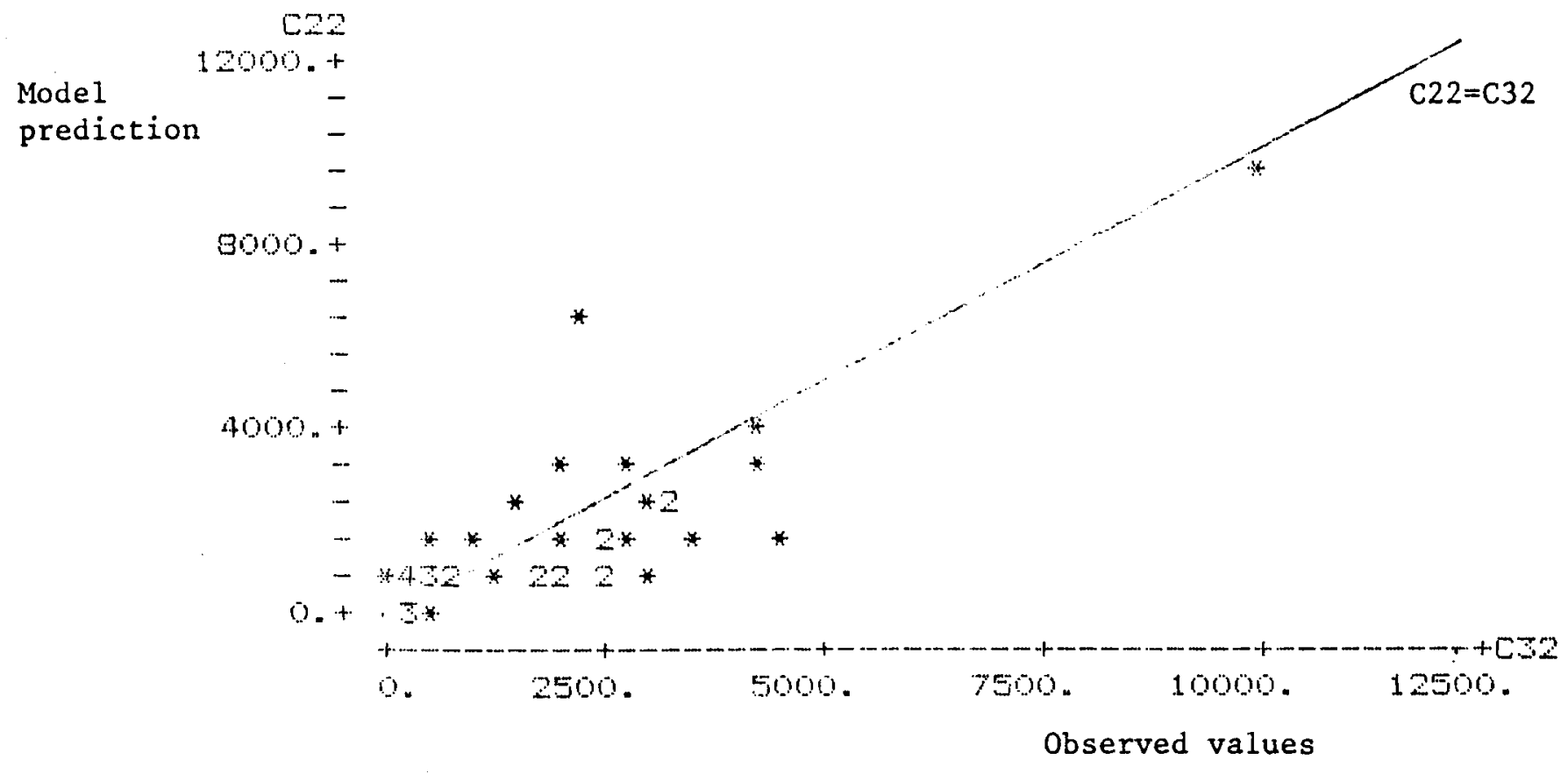

Figure $A: 1$ Dbserved value ( $p$ lant cost) vs. model prediction for $P$ \& $P$ firm cost function (see table 1, p. 9). 